\title{
USO DE REGULADORES DE CRESCIMENTO COMO POTENCIALIZADORES DO PERFILHAMENTO E DA PRODUTIVIDADE EM CANA-SOCA $\left({ }^{\mathbf{1}}\right)$
}

\author{
MARCELO DE ALMEIDA SILVA $\left({ }^{2 *}\right)$; GLAUBER JOSÉ DE CASTRO GAVA $\left({ }^{2}\right)$; \\ MARINA MAITTO CAPUTO $\left({ }^{3}\right)$; RENATA PASSOS PINCELLI $\left({ }^{4}\right)$; \\ ELISANGELA MARQUES JERÔNIMO $\left({ }^{2}\right)$; JULIANA CRISTINA SODÁRIO CRUZ $\left({ }^{2}\right)$
}

\begin{abstract}
RESUMO
O uso de reguladores de crescimento como indutores da maturação em cana-de-açúcar tem sido uma prática agrícola com resultados bem solidificados. Entretanto, o efeito residual desses compostos na cana-soca seguinte é pouco estudado. Esta pesquisa objetivou avaliar o efeito residual de dois reguladores vegetais, aplicados antes da colheita, na brotação da cana-soca e na produtividade de três genótipos de cana-de-açúcar. O ensaio foi realizado na região de Jaú (SP). O delineamento experimental foi o de blocos casualizados, em parcelas subdivididas, com quatro repetições, constituído pela combinação dos genótipos IAC87-3396, IAC91-2195 e IAC91-5155, e de três formas de manejos da cultura: sulfometuronmetil, $20 \mathrm{~g} \mathrm{ha}^{-1}$; etefon, $480 \mathrm{~g}$ i.a. ha ${ }^{-1}$ e testemunha. A aplicação dos reguladores vegetais ocorreu 126 dias antes do corte das touceiras. Foram realizadas avaliações para quantificar o número de perfilhos $\mathrm{m}^{-1}$ aos 0,90,180, 270 e 360 dias após o corte; a porcentagem de colmos por metro final em relação à inicial; a massa de 10 colmos, o comprimento e o diâmetro médios dos colmos; a pol e a fibra \% cana, os açúcares redutores e total recuperável, e a produtividade de colmos e de açúcar. Concluiu-se que houve efeito estimulante na emergência do perfilhamento até seis meses após o corte. O etefon promoveu maiores produtividades de colmos e de açúcar. Houve diferenças entre genótipos quanto à resposta do comprimento de colmos na cana-soca em relação aos reguladores vegetais. Não houve efeito sobre a qualidade tecnológica da cana-de-açúcar na cana-soca seguinte.
\end{abstract}

Palavras-chave: Saccharum spp., brotação da cana-soca, etefon, sulfometuron-metil, produção.

\section{ABSTRACT \\ USE OF PLANT GROWTH REGULATORS AS IMPROVERS OF TILLERING AND OF PRODUCTIVITY IN SUGARCANE RATOON}

The use of plant growth regulators as ripeners in sugarcane has been an agronomic practice with well solidified results. However, the residual effect of these products over the next ratoon is still not very well studied. This research aimed to evaluate the residual effect of two plant growth regulators, applied before the harvest, in the stool regrowth and productivity of three sugarcane genotypes. The experiment was carried out near Jaú (SP). The experimental design was a randomized complete block, in split-plot, with four repetitions, constituted by the genotypes IAC87-3396, IAC91-2195 and IAC91-5155, and by three crop management: $20 \mathrm{~g} \mathrm{ha}^{-1}$ sulfomethuron-methyl; $480 \mathrm{~g}$ a.i. ha ${ }^{-1}$ ethephon and control. The growth regulators were applied 126 days before harvest. To quantify the action of growth regulators the following variables were evaluated: the number of tillers $\mathrm{m}^{-1}$ at $0,90,180,270$ and 360 days after the harvest; the final percentage of stalk number by meter in relation to the initial percentage; the mass of

( $\left.{ }^{1}\right)$ Recebido para publicação em 28 de dezembro de 2006 e aceito em 18 de maio de 2007.

$\left({ }^{2}\right)$ APTA Regional Centro-Oeste, Caixa Postal 66, 17201-970 Jaú (SP). E-mail: marcelosilva@aptaregional.sp.gov.br. $\left({ }^{*}\right)$ Autor correspondente.

$\left({ }^{3}\right)$ Departamento de Produção Vegetal, ESALQ/USP, Caixa Postal 9, 13418-900 Piracicaba (SP). Bolsista CNPq. E-mail: marinamaittocaputo@hotmail.com

$\left({ }^{4}\right)$ Graduanda de Biologia da Universidade Sagrado Coração, Bauru, SP. Bolsista FUNDAP. 
10 stalks, the length and the diameter of stalks; the pol and the fiber\% cane, the reducing and total recoverable sugars, and the productivity of stalks and sugar. It was concluded that there was stimulating effect on the emergency of tillering up to six months after the harvest. The ethephon promoted larger productivities of stalks and sugar. There were differences among genotypes in relation to growth regulators for stalk length. There was no effect on the technological quality over the subsequent ratoon crop.

Key words: Saccharum spp., ratoon emergence, ethephon, sulfomethuron-methyl, yield.

\section{INTRODUÇÃO}

Na produção de sacarose da cana-de-açúcar, provavelmente, o fator mais importante relacionado com o processo é o número de colmos por unidade de área na colheita. Para se obter o número máximo de colmos suportáveis na área é necessário induzir ramificações na fase inicial de desenvolvimento da planta. Um perfilho é uma ramificação (colmo) originária da base da planta ou da região axilar da folha basal, sendo geralmente característico das gramíneas. A intensidade do perfilhamento é variável entre as diferentes cultivares, podendo ocorrer até quatro meses após o plantio (10 a 20 perfilhos), com posterior decréscimo no número de brotações, em virtude da competição natural por luz, água e nutrientes (CAstro e Christofoletti, 2005). Nas gramíneas em touceiras, como a cana-de-açúcar, a ramificação subsuperficial é limitada, ocorrendo a formação de inúmeras hastes eretas, caracterizando o conjunto como plantas individuais (Dillewijn, 1952).

Segundo Landell e Silva (2004), os atributos de produção determinantes para a formação do potencial agrícola são: altura de colmo $(\mathrm{h})$, número de perfilhos (C) e diâmetro de colmos (d). Considerando-se a densidade do colmo igual a 1,0, o valor da tonelada de cana por hectare $(\mathrm{TCH})$ pode ser estimada pela fórmula abaixo, no espaçamento entre os sulcos (E):

$$
\mathrm{TCH}=\frac{\mathrm{d}^{2} \times \mathrm{C} \times \mathrm{h}(0,007854)}{\mathrm{E}}
$$

Diversos trabalhos já foram desenvolvidos para se verificar o efeito de reguladores de crescimento, aplicados em pré (CASTRO et al., 1975a; CAstro et al., 1975b; CASTRO et al., 1981; Verri et al., 1983; Melotto et al., 1987; Millhollon e Legendre, 1995; WIEDENFELD, 2003) ou pós-emergência (LuCCHESI et al., 1979; Shetiya e Dendsay, 1991; Millhollon e LEGENDRE, 1995), na brotação e no desenvolvimento inicial da cana-de-açúcar, objetivando maiores perfilhamento e produção final de colmos.

Alguns compostos comumente utilizados como maturadores têm sido considerados eficientes na indução de maior perfilhamento da cana-deaçúcar, dentre eles o ácido (2-cloroetil) fosfônico (etefon). Essa substância é tida como regulador de crescimento de plantas, com propriedades sistêmicas. Nas plantas, o etefon rapidamente sofre degradação para ácido fosfórico, etileno e íons cloreto, tendo efeito sobre o processo de crescimento (TomLIn, 1994).

Sulfometuron-metil, pertencente ao grupo das sulfuniluréias, tem-se revelado eficiente como maturador da cana-de-açúcar. Esse grupo parece não bloquear promotores de crescimento, estimula fortemente a produção de etileno pela ação estressante, não inibe a alongação celular nem a síntese protéica e de RNA. Em doses subletais, promove pequeno crescimento vegetativo (CASTRO et al., 1996).

Apesar dos efeitos positivos, alguns reguladores de crescimento utilizados como maturadores podem ter efeito colateral, prejudicando a cana-soca seguinte. Segundo Julien (1997), de dez experimentos realizados com Polaris (produto comercial), em quatro deles ocorreu uma pobre brotação da cana-soca. O mesmo autor salientou que fatores como o ambiente, o estádio de desenvolvimento da cultura na época de aplicação do produto químico, os intervalos entre a data de aplicação e a colheita, a concentração química e o uso de substâncias de baixa deriva (Nalco-trol) podem afetar a rebrota. De acordo com RoMEro et al. (2000), doses elevadas de glifosate, superiores a 0,43 L i.a. ha ${ }^{-1}$, podem causar retardamento do processo de brotação e crescimento da cultura no ciclo seguinte, além de causar amarelecimento severo e dessecamento das plantas.

O conhecimento do efeito dos reguladores de crescimento etefon e sulfometuron-metil aplicados como maturadores sobre a cana-soca seguinte é escasso. O presente estudo objetivou avaliar o efeito residual desses dois produtos sobre a cana-soca subseqüente, aplicados como maturadores, na emergência, na biometria, na qualidade e na produtividade de três genótipos.

\section{MATERIAL E MÉTODOS}

O experimento foi realizado na Unidade de Pesquisa e Desenvolvimento de Jaú (SP), da Agência Paulista de Tecnologia dos Agronegócios (APTA) Regional Centro-Oeste, localizada na latitude de $22^{\circ}$ $17^{\prime} \mathrm{S}$, longitude $48^{\circ} 34^{\prime} \mathrm{W}$, e altitude de $580 \mathrm{~m}$. O solo da área é Latossolo Vermelho Eutroférrico com A 
moderado e textura argilosa, segundo PRADO (2003). O clima predominante da região é o Aw (Köppen), com clima seco definido, temperatura média anual de $21,6^{\circ} \mathrm{C}$, umidade relativa média de $70 \%$, com extremos de $99 \%$ em fevereiro e $19 \%$ em agosto. A média pluviométrica anual é de $1.344 \mathrm{~mm}$.

O delineamento experimental utilizado foi o de blocos casualizados, em parcelas subdivididas, com quatro repetições, constituído pela combinação de três genótipos como tratamentos principais: IAC873396, IAC91-2195; e IAC91-5155, e de três manejos da cultura como tratamentos secundários: sulfometuronmetil, $20 \mathrm{~g} \mathrm{ha}^{-1}$; etefon, $480 \mathrm{~g}$ i.a. $\mathrm{ha}^{-1}$ e testemunha, totalizando nove tratamentos. As parcelas constituíram-se de cinco sulcos de 10 metros de comprimento, espaçados entre si por 1,5 m.

O plantio da área foi realizado em 26 de julho de 2002 e o primeiro corte ocorreu em 10 de junho de 2003. A aplicação dos reguladores de crescimento ocorreu em 10 de março de 2004, com a finalidade de agirem como maturadores.

A aplicação dos produtos químicos reguladores de crescimento foi feita com equipamento pressurizado por cilindro de $\mathrm{CO}_{2}$ comprimido, conectado a uma garrafa de PVC, com a calda preparada, ligada aos bicos, um acima de cada linha (do tipo Magnum defletor 0,50, de latão, anteriormente testados para igualar a vazão), sustentados por uma barra de ferro de $6,0 \mathrm{~m}$ em forma de $\mathrm{U}$ invertido, suspensa por dois indivíduos, caminhando na mesma velocidade. Um dos indivíduos também conduzia a garrafa contendo a calda do produto químico e a alavanca utilizada para acionar ou interromper a aspersão. A pressão de trabalho foi de $40 \mathrm{lb} \mathrm{pol}^{-2}$ para a vazão de $40 \mathrm{~L} \mathrm{ha}^{-1}$. A concentração da calda foi calculada de acordo com a vazão verificada anteriormente, para obtenção da dose praticada no experimento.

A condição climática no momento da aplicação era de umidade relativa do ar de $65 \%$ a $91 \%$ e de temperaturas de 18 a $28,5^{\circ} \mathrm{C}$, sem a ocorrência de ventos. Não ocorreram chuvas, em nenhuma das aplicações, antes de decorridas seis horas da aplicação.

O segundo corte das parcelas ocorreu em 14 de julho de 2004, isto é, 126 dias após a aplicação dos produtos. Antecedendo esse corte, foram contados os perfilhos de cada parcela para indicação do ponto zero das contagens subseqüentes de perfilhamento.

Foram realizadas avaliações para quantificar o número de perfilhos por metro linear durante o período de desenvolvimento da cultura. Assim, as avaliações foram: aos 90, 180, 270 e 360 dias após o segundo corte. Na última data foi realizada a colheita do experimento. Com o número de perfilhos por metro obtido na primeira e na última avaliação, calculouse a porcentagem final de colmos por metro, em relação à inicial.

Por ocasião da colheita, feita aos 12 meses após o segundo corte, amostraram-se 10 colmos seguidos na linha, em cada parcela, para efetuar a biometria e obter dados de massa de 10 colmos, de comprimento e diâmetro médios dos colmos (LANDELL e SiLva, 1995). As amostras foram encaminhadas para o Laboratório de Tecnologia da Associcana, em Jaú, para as análises e obtenção dos valores de Pol \% cana, Fibra \% cana, Açúcares Redutores e Açúcar Total Recuperável (ATR), conforme ConseCANA (2003). Os colmos de cada parcela foram cortados e contados. De cada parcela foram obtidas as massas totais de colmos através de balança tipo célula de carga graduada em $200 \mathrm{~g}$. Em seguida foi obtida a produtividade de colmos, em tonelada de cana por hectare $(\mathrm{TCH})$, por meio da relação com a área da parcela. A tonelada de pol por hectare (TPH) foi obtida pelo produto entre a produtividade de colmos $(\mathrm{TCH})$ e a Pol \% cana-de-açúcar.

Os resultados foram submetidos à análise de variância e utilizou-se teste de Tukey a $5 \%$ de probabilidade para a comparação de médias.

\section{RESULTADOS E DISCUSSÃO}

Nas figuras 1, 2 e 3, observa-se a evolução do perfilhamento para os genótipos IAC87-3396, IAC912195 e IAC91-5155 respectivamente. Houve um incremento do número de perfilhos por metro, até 180 dias após o corte da cana-soca e, após esse período, uma drástica redução nesse número, ocorrendo sua estabilização entre 270 e 360 dias, independentemente dos reguladores de crescimento aplicados. No ponto de máximo perfilhamento esse número variou de 18,9 a 21,1 para IAC87-3396, de 18,5 a 22,6 para IAC $91-2195$ e de 21,5 a 25,2 para IAC91-5155. Aos doze meses de idade da cana-soca os valores de número de perfilhos por metro variaram na ordem de 8,7 a 10,3 para IAC87-3396, de 10,9 e 12,0 IAC91-2195 e de 10,1 a 10,8 para IAC91-5155. Esse aumento no perfilhamento em até 6 meses de idade e posterior redução de cerca de $50 \%$, seguida de estabilização tanto em cana-planta quanto em cana-soca, a partir dos 9 meses, é uma característica fisiológica da cana-de-açúcar, que já foi observada por vários autores (DILlewiJn, 1952; BARBIERI, 1993; Prado, 1988, Daros et al., 1999; Silva et al. 2002; Castro e Christofoletti, 2005). 


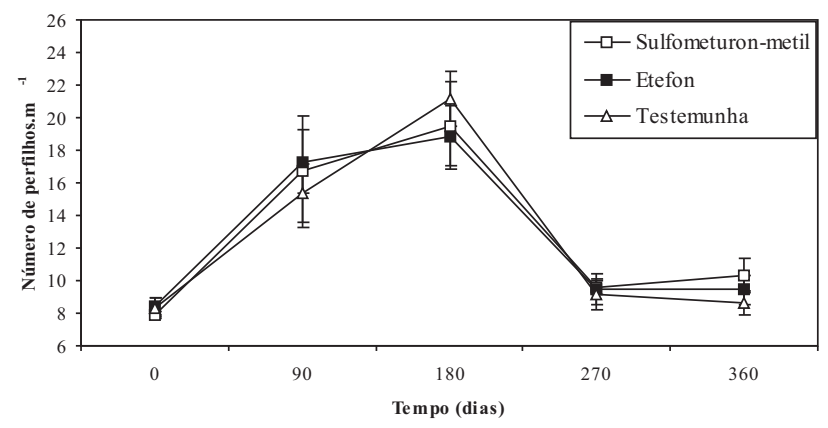

Figura 1. Número de perfilhos por metro do genótipo IAC87-3396, no período de zero a 12 meses de idade, em cana-de-açúcar de segundo corte, após a aplicação de sulfometuron-metil e etefon.

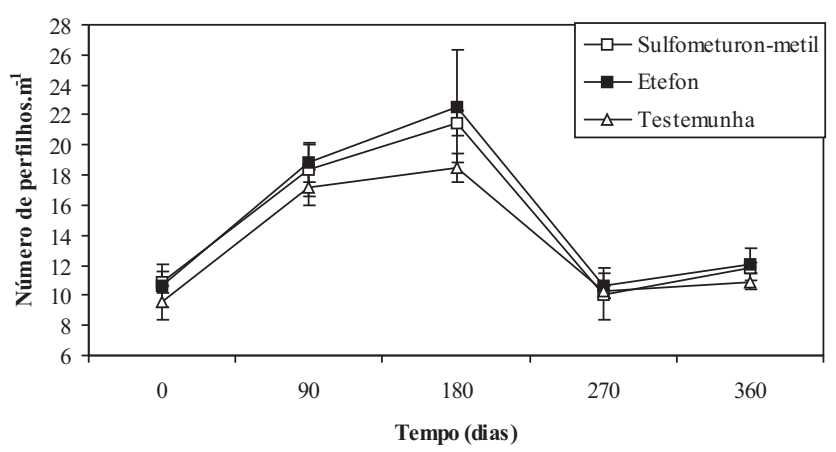

Figura 2. Número de perfilhos por metro do genótipo IAC91-2195, no período de zero a 12 meses de idade, em cana-de-açúcar de segundo corte, após a aplicação de sulfometuron-metil e etefon.

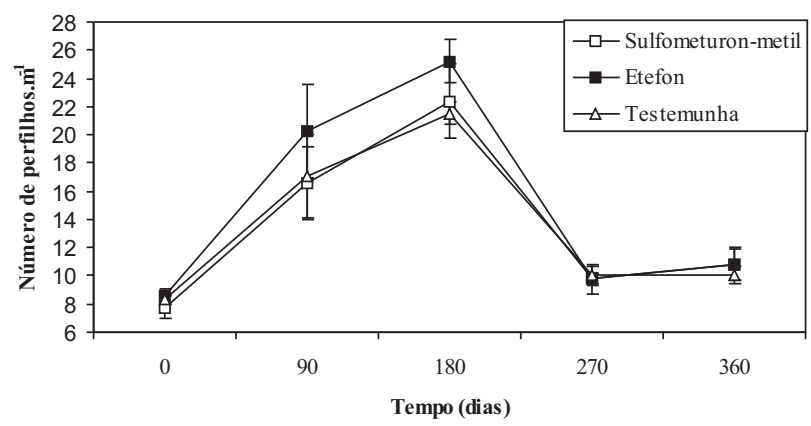

Figura 3. Número de perfilhos por metro do genótipo IAC91-5155, no período de zero a 12 meses de idade, em cana-de-açúcar de segundo corte, após a aplicação de sulfometuron-metil e etefon.

Ao analisar o efeito dos reguladores de crescimento aplicados 126 dias antes do corte da cana-de-açúcar no perfilhamento da cana-soca subseqüente, verificam-se diferentes respostas entre genótipos e produtos. Na figura 1 nota-se a evolução do perfilhamento do genótipo IAC87-3396, cuja aplicação tanto de etefon, quanto de sulfometuronmetil, proporcionou, aos três meses, incremento do perfilhamento, maior que o da testemunha. Entretanto, aos seis meses, esse incremento não se manteve $\mathrm{e}$ observou-se maior perfilhamento na testemunha, em relação aos demais tratamentos. Aos nove meses após o corte dos colmos, houve severa redução do perfilhamento em relação à avaliação anterior, não se observando diferença significativa entre os tratamentos. Dos nove para os doze meses de idade da cana-soca, praticamente houve a estabilização dos números de perfilhos por metro, mas no tratamento com sulfometuron-metil o perfilhamento final foi maior do que na testemunha.

Para o genótipo IAC91-2195 (Figura 2), o etefon proporcionou maior perfilhamento que a testemunha em número absoluto aos três meses, e significativamente diferente aos seis meses. Porém, assim como para o genótipo anterior, os valores de perfilhamento decresceram acentuadamente na avaliação seguinte e se mantiveram até os doze meses, não havendo diferenças significativas entre os tratamentos no número final de perfilhos por metro.

Maior efeito do etefon sobre o perfilhamento foi observado para o genótipo IAC91-5155 até os seis meses após o corte (Figura 3). Em compensação, nenhum efeito do sulfometuron-metil sobre o genótipo foi constatado, pois o número médio de perfilhos por metro não diferenciou da testemunha em nenhuma das avaliações.

Em outros estudos também já se verificou que genótipos de cana-de-açúcar respondem diferentemente ao etefon quanto ao aumento de perfilhamento no início do desenvolvimento. MilLhollon e Legendre (1995) observaram, em seis genótipos avaliados, que as respostas variam tanto na itensidade do perfilhamento quanto na época e na duração da ocorrência. WIEDENFELD (2003) observou aumento do perfilhamento em três de cinco genótipos estudados, e argumentou que quando são observadas respostas diferentes de genótipos aos reguladores de crescimento, faz-se necessário uma calibração de dose e época de aplicação baseada na resposta desejada para cada genótipo.

Apesar de o número de perfilhos por metro aos 12 meses de idade ter sido significativamente igual para os três manejos, para os três genótipos avaliados é importante ressaltar o efeito do etefon e do sulfometuron-metil sobre IAC91-2195 e do etefon sobre IAC91-5155 até os seis meses após o corte. Esse crescimento inicial rápido e uniforme permite atingir bom estande, possibilitando rápido fechamento de entrelinha com controle mais efetivo das plantas daninhas, além de cobertura do solo homogênea, o que leva a um eficiente aproveitamento da energia luminosa pela planta. 
Resultados semelhantes quanto ao aumento inicial rápido do perfilhamento foram encontrados por Millhollon e LeGENDRE (1995) e Wiedenfeld (2003), que aplicaram etefon na pré-emergência de diversos genótipos. Nesses trabalhos, os autores observaram que a população de colmos aumentou até 270 e 120 dias, respectivamente, após a emergência dos perfilhos tanto no tratamento quanto na testemunha, porém com vantagem para o tratamento com etefon. Contudo, esse efeito tendeu a desaparecer no decorrer do tempo, não sendo encontrada diferença entre testemunha e etefon para população de colmos durante a colheita. Dessa forma, sendo a população de colmos diretamente relacionada com a produção, os autores ponderaram que o etefon tem um potencial limitado para ser usado como um promotor de aumento da produção de canade-açúcar, entretanto, seu uso foi promissor quando se utilizou o espaçamento de linhas duplas ou se reduziu a quantidade de muda recomendada no plantio. Shetiya e Dendsay (1991) ainda protagonizaram que etefon pode ser usado em pósemergência quando existem falhas na brotação.

Como no fundamento esses dois reguladores têm a mesma ação na planta, isto é, aumentam a concentração de etileno, NaILWAL et al. (2004) esclarecem que o efeito do etileno, tanto em pré-tratamento dos colmos de canade-açúcar quanto em aplicação foliar, é de inibição do transporte de auxina. Com a diminuição da concentração da auxina, quebra-se a dominância apical e, portanto, estimula-se a produção de novas ramificações (perfilhos). Entretanto, esse efeito é temporário, e o equilíbrio entre a interação etileno e auxina retorna ao normal, quando então a competição interplantas por luz, água e nutrientes prevalece. Millhollon e Legendre (1995) concluíram que a competição interplantas é o maior limitador para aumentar população de colmos com etefon. Assim, como com o uso de sulfometuron-metil houve resultado semelhante, este estudo revela que essa competição interplantas é o grande limitador para aumentar população de colmos com produtos que estimulam o aumento de etileno na planta.

$\mathrm{Na}$ tabela 1, observa-se que não houve diferenças entre os genótipos para os atributos \% de número perfilhos por metro final em relação ao inicial (P), massa de 10 colmos (M10), tonelada de colmos por hectare $(\mathrm{TCH})$ e tonelada de açúcar por hectare (TPH). Houve diferenças entre os genótipos em relação ao comprimento (C) e diâmetro (D) de colmos, e essas diferenças são atribuídas à própria característica genética de cana genótipo.

Destaca-se que houve aumento do número final de perfilhos por metro linear entre as contagens inicial e final, independentemente do uso ou não dos reguladores, a qual variou de 13,14 a $28,73 \%$ para os genótipos IAC91-2195 e IAC91-5155 respectivamente.
Para manejo, os valores obtidos foram de 13,66 para a testemunha e de 17,98 e $26,31 \%$ para o etefon e o sulfometuron-metil respectivamente. LuCCHESI et al. (1979) constataram um acréscimo de 48,20 \% na quantidade de colmos entre dois cortes com a aplicação de etefon na dose de $480 \mathrm{~L} \mathrm{ha}^{-1}$ de i.a., aos 40 dias de idade, no estudo com a variedade NA56-79. MiLLHOLLON E LEGENDRE (1995) obtiveram aumento, porém não consistente, na população final de colmos em relação ao ciclo anterior apenas com aplicação em pósemergência de etefon; os valores variaram conforme a variedade, em que três das seis estudadas responderam, e foram mais uniformes quando o espaçamento de linha dupla foi utilizado.

Na avaliação da ação dos reguladores, verificase que apenas em TCH e TPH houve diferenças significativas. As parcelas tratadas com etefon produziram em média 100,44 tha ${ }^{-1}$, diferenciando-se da testemunha que produziu $89,41 \mathrm{tha}^{-1}$, em todos os genótipos avaliados. As parcelas tratadas com sulfometuron-metil produziram em média $96,56 \mathrm{t} \mathrm{ha}^{-1}$. O mesmo ocorreu para a TPH, tratando-se de um reflexo do TCH, uma vez que a pol \% cana (Tabela 3) praticamente não variou. Esses resultados diferem dos obtidos por Millhollon e Legendre (1995), que não observaram diferenças entre as variedades tratadas com etefon e a testemunha. As diferenças encontradas neste estudo, possivelmente, são devidas à combinação de todos os atributos que compõem a produtividade, conforme descrito por LANDELl e SILVA (2004), sendo, particularmente, neste caso, sob maior influência do número final de perfilhos, que em números absolutos foi maior nos tratamentos com etefon e sulfometuronmetil (Figuras 1, 2 e 3).

Na tabela 2 são apresentados os valores de comprimento de colmos (C) para o desdobramento da interação Genótipos x Reguladores de crescimento. Nos genótipos IAC87-3396 e IAC91-2195 não se verificaram diferenças significativas entre os manejos. Porém, na IAC91-5155 notou-se efeito negativo do uso de etefon, cujo comprimento médio dos colmos foi reduzido em $38,25 \mathrm{~cm}$. LuCCHESI et al. (1979) também observaram redução do comprimento quando houve aplicação de etefon de $480 \mathrm{~L} \mathrm{ha}^{-1}$ de i.a., porém com aplicação aos 40 dias de idade. Millhollon e Legendre (1995) obtiveram, tanto com aplicação em pré quanto em pós-emergência de etefon, redução do comprimento de colmos em todas as variedades avaliadas, apesar de que nem todas as diferenças foram significativas. De acordo com RoDRIGUES (1995), o etefon, pela ação retardadora do etileno, reduz o crescimento dos entrenós do colmo desenvolvidos na época da pulverização, visto que os entrenós formados posteriormente retomam o crescimento normal. Nas plantas, apesar de mais baixas, nota-se que os colmos aproveitáveis atingem maior proporção na planta, ocorrendo descarte de uma menor região apical (palmito). 
Tabela 1. Porcentagem de número de perfilhos por metro final em relação ao inicial (P), massa de dez colmos (M10), comprimento de colmos (C), diâmetro de colmos (D), produtividade de colmos (TCH) e produtividade de açúcar (TPH) de três genótipos submetidos a três manejos de condução da cultura em pré-colheita

\begin{tabular}{|c|c|c|c|c|c|c|c|}
\hline \multicolumn{2}{|l|}{ Tratamentos } & \multirow{3}{*}{$\begin{array}{c}\mathrm{P} \\
\% \\
16,09 \mathrm{a}\end{array}$} & \multirow{3}{*}{$\begin{array}{c}\mathrm{M} 10 \\
\mathrm{~kg} \\
14,05 \mathrm{a}\end{array}$} & \multirow{2}{*}{\multicolumn{2}{|c|}{$\begin{array}{cc}\mathrm{C} & \mathrm{D} \\
& \mathrm{cm}-\end{array}$}} & \multirow{2}{*}{\multicolumn{2}{|c|}{$\begin{array}{cr}\mathrm{TCH} & \mathrm{TPH} \\
& \mathrm{t} \cdot \mathrm{ha}^{-1} \longrightarrow\end{array}$}} \\
\hline & & & & & & & \\
\hline \multirow[t]{3}{*}{ Genótipos } & IAC87-3396 & & & $234,50 a b$ & $2,68 \mathrm{a}$ & 94,16 a & $14,87 \mathrm{a}$ \\
\hline & IAC91-2195 & $13,14 \mathrm{a}$ & $10,88 \mathrm{a}$ & $216,50 \mathrm{~b}$ & $2,39 \mathrm{~b}$ & $91,12 \mathrm{a}$ & $15,05 \mathrm{a}$ \\
\hline & IAC91-5155 & $28,73 \mathrm{a}$ & $14,63 \mathrm{a}$ & $259,58 \mathrm{a}$ & $2,55 \mathrm{ab}$ & 101,13 a & $16,33 \mathrm{a}$ \\
\hline \multirow[t]{3}{*}{ Reguladores } & Sulfometuron-metil & $26,31 \mathrm{a}$ & $13,03 \mathrm{a}$ & $241,67 \mathrm{a}$ & $2,54 \mathrm{a}$ & $96,56 \mathrm{ab}$ & $15,58 \mathrm{ab}$ \\
\hline & Etefon & $17,98 \mathrm{a}$ & $12,97 \mathrm{a}$ & $228,17 \mathrm{a}$ & $2,53 \mathrm{a}$ & 100,44 a & $16,23 \mathrm{a}$ \\
\hline & Testemunha & $13,66 \mathrm{a}$ & 13,57 a & 240,75 a & $2,55 \mathrm{a}$ & $89,41 \mathrm{~b}$ & $14,44 \mathrm{~b}$ \\
\hline \multirow[t]{3}{*}{$\mathrm{F}$} & Genótipo (G) & 3,71 & 3,74 & $4,76^{*}$ & $6,61^{*}$ & 0,87 & 0,66 \\
\hline & Regulador (R) & 2,67 & 0,39 & 3,51 & 0,05 & $6,42 * *$ & $4,20 *$ \\
\hline & $G \times R$ & 1,74 & 0,88 & $3,40^{*}$ & 1,36 & 1,49 & 1,02 \\
\hline \multicolumn{2}{|c|}{ C.V. parcela (\%) } & 12,48 & 27,45 & 14,51 & 7,64 & 19,93 & 22,05 \\
\hline \multicolumn{2}{|c|}{ C.V. subparcela (\%) } & 11,42 & 13,84 & 5,89 & 6,25 & 8,01 & 9,94 \\
\hline
\end{tabular}

Médias seguidas de mesma letra dentro de cada atributo (genótipos e reguladores de crescimento) não diferem estatisticamente, a $5 \%$ de probabilidade, pelo teste de Tukey. ${ }^{*},{ }^{* *}$ : significativo a $5 \%$ e a $1 \%$ respectivamente.

Tabela 2. Desdobramento da interação Genótipo x Reguladores de crescimento referente a comprimento de colmos (cm)

\begin{tabular}{lccc}
\hline Reguladores de crescimento & \multicolumn{3}{c}{ Genótipos } \\
\cline { 2 - 4 } & IAC87-3396 & IAC91-2195 & IAC91-5155 \\
\hline Sulfometuron-metil & 247,75 a A & 218,75 a B & 258,50 ab A \\
Etefon & 228,00 a AB & 215,50 a B & 241,00 b A \\
Testemunha & 227,75 a B & 215,25 a B & 279,25 a A \\
DMS & 25,20 & - & - \\
\hline
\end{tabular}

Médias seguidas de letras diferentes, minúsculas na coluna e maiúsculas na linha, diferem estatisticamente, a 5\% de probabilidade pelo teste de Tukey.

Tabela 3. Pol da cana (PCC), fibra da cana (F), açúcares redutores da cana (AR) e açúcar total recuperável (ATR) de três genótipos submetidos a três manejos de condução da cultura em pré-colheita

\begin{tabular}{|c|c|c|c|c|c|}
\hline Tratamentos & & PCC & $\mathrm{F}$ & $\mathrm{AR}$ & ATR \\
\hline & & & - $\%$ & - & $\mathrm{kg} \mathrm{t}^{-1}$ \\
\hline \multirow[t]{3}{*}{ Genótipos } & IAC87-3396 & $15,76 \mathrm{~b}\left({ }^{1}\right)$ & $13,67 \mathrm{a}$ & $0,48 \mathrm{a}$ & $149,54 \mathrm{~b}$ \\
\hline & IAC91-2195 & $16,53 \mathrm{a}$ & $12,86 \mathrm{~b}$ & $0,47 \mathrm{a}$ & 156,60 a \\
\hline & IAC91-5155 & $16,09 \mathrm{ab}$ & $12,96 \mathrm{~b}$ & $0,53 \mathrm{a}$ & $152,86 \mathrm{ab}$ \\
\hline \multirow[t]{3}{*}{ Reguladores } & Sulfometuron-metil & $16,11 \mathrm{a}$ & 13,18 a & $0,49 \mathrm{a}$ & 152,84 a \\
\hline & Etefon & $16,14 \mathrm{a}$ & 13,04 a & $0,49 \mathrm{a}$ & 153,16 a \\
\hline & Testemunha & $16,13 \mathrm{a}$ & $13,28 \mathrm{a}$ & $0,49 \mathrm{a}$ & $153,00 \mathrm{a}$ \\
\hline \multirow[t]{3}{*}{$\mathrm{F}$} & Genótipo (G) & $5,37^{*}$ & $8,69^{* *}$ & 3,67 & $5,33^{*}$ \\
\hline & Regulador (R) & 0,01 & 1,30 & 0,18 & 0,01 \\
\hline & $G \times R$ & 0,06 & 1,23 & 0,88 & 0,06 \\
\hline C.V. parcela (\%) & & 3,57 & 3,94 & 8,06 & 3,46 \\
\hline C.V. subparcela (\%) & & 3,66 & 2,76 & 5,21 & 3,50 \\
\hline
\end{tabular}

Médias seguidas de mesma letra dentro de cada atributo (genótipos e reguladores de crescimento) não diferem estatisticamente, a $5 \%$ de probabilidade, pelo teste de Tukey. ${ }^{*}{ }^{* *}$ : significativo a $5 \%$ e a $1 \%$ respectivamente 
O sulfometuron-metil também reduziu o comprimento dos colmos em relação à testemunha, mas em menor proporção $(20,75 \mathrm{~cm})$; entretanto, essa diferença não foi significativa. Concordando com RodRIGUEs (1995), quando afirmou que sulfometuronmetil restringe o crescimento e a divisão celular de forma transitória promovendo epinastia; e com CASTRO et al. (1994) que obtiveram restrição no crescimento do colmo e na formação foliar da cana-de-açúcar, cultivar SP70-1143.

Não foi verificado nenhum efeito dos reguladores de crescimento sobre a qualidade tecnológica da cana-soca subseqüente dos três genótipos (Tabela 3). Portanto, os produtos aplicados como maturadores no ciclo anterior não promoveram o efeito de melhorar as características tecnológicas da cana-de-açúcar no ciclo seguinte, assim como, também, não prejudicaram essas características. As diferenças entre os valores de Pol \% cana (PCC), Fibra \% cana (F) e Açúcar Teórico Recuperável (ATR) podem ser atribuídas à própria divergência genética inerente a cada genótipo.

\section{CONCLUSÕES}

1. Os reguladores de crescimento aplicados antes da colheita da cana-de-açúcar não prejudicaram a brotação da cana-soca seguinte.

2. Houve efeito estimulante na emergência da brotação e perfilhamento, observado até seis meses após o corte da cana-de-açúcar.

3. O etefon promoveu maiores produtividades de colmos e de açúcar na cana-soca subseqüente.

4. Houve diferenças entre genótipos quanto à resposta do comprimento de colmos em relação aos reguladores de crescimento sulfometuron-metil e etefon.

5. Para o genótipo IAC91-5155, o uso de sulfometuron-metil e etefon reduziu o comprimento de colmos na cana-soca seguinte.

6. Não houve efeito dos reguladores de crescimento sobre a qualidade tecnológica da canade-açúcar.

\section{AGRADECIMENTOS}

Agradecemos à empresa DuPont pelo suporte financeiro. Aos técnicos de apoio Valdir Lotti e Marcos Alexandre Aparecido Pereira pela colaboração na condução e colheita do ensaio, e a Aline Vanessa Zambello pela digitação dos dados.

\section{REFERÊNCIAS}

BARBIERI, V. Condicionamento climático da produtividade potencial da cana-de-açúcar (Saccharum spp.): um modelo matemático-fisiológico de estimativa. Piracicaba, 1993. 142 f. Tese (Doutorado em Agronomia) - Departamento de Física e Meteorologia - ESALQ-USP.

CASTRO, P.R.C., CÂMARA, G.M.S., CESAR, M.A.A., NOGUEIRA, M.C.S. Ação comparada de maturadores em dois cultivares de cana-de-açúcar. Álcool \& Açúcar, São Paulo, n.73, p.36-39, 1994.

CASTRO, P.R.C.; CHRISTOFFOLETI, P.J. Fisiologia da cana-de-açúcar. In: MENDONÇA, A.F. Cigarrinhas da canade-açúcar: Controle biológico. 1.ed. Maceió: Insecta, 2005. p.3-48.

CASTRO, P.R.C.; OLIVEIRA, D.A.; PANINI, E.L. Ação do sulfometron metil como maturador da cana-de-açúcar. In: CONGRESSO NACIONAL DA SOCIEDADE DOS TÉCNICOS AÇUCAREIROS E ALCOOLEIROS DO BRASIL - STAB, 6, 1996, Maceió. Anais... Maceió: Sociedade dos Técnicos Açucareiros e Alcooleiros do Brasil, 1996, p. 363-369.

CASTRO, P.R.C.; SANGUINO, A.; DEMÉTRIO, C.G.B. Efeitos de reguladores vegetais no crescimento inicial da cana-de-açúcar. Brasil Açucareiro, Rio de Janeiro, v.98, n.5, p. 47-51, 1981.

CASTRO, P.R.C.; SANGUINO, A.; VILELA, E.; AKIBA, F.; SUDO, S.; MASUDA, Y. Ação de reguladores de crescimento no desenvolvimento inicial da cana-de-açúcar tratada termicamente. Brasil Açucareiro, Rio de Janeiro, v.85, n.5, p. 42-50, $1975 b$.

CASTRO, P.R.C.; SERRA, G.E.; RUGAI, S.; ORLANDO FILHO, J.; NASCIMENTO FILHO, V.F.; SOUSA, J.A.G.C. Efeitos de reguladores de crescimento no enraizamento e desenvolvimento inicial da cana-de-açúcar cultivar Co 740. Suplemento Ciência e Cultura, São Paulo, v.27, n.7, p. 627, 1975a.

CONSECANA. Manual de Instruções. 4. ed. Piracicaba: Conselho dos Produtores de Cana-de-Açúcar. Açúcar e Álcool do Estado de São Paulo, 2003. 115p.

DAROS, E.; ZAMBON, J.L.C.; WEBER, H.; IDO, O.T.; GRACIANO, P.A. Efeito da densidade de plantio em duas variedades de cana-de-açúcar. In: CONGRESSO NACIONAL DA SOCIEDADE DOS TÉCNICOS AÇUCAREIROS E ALCOOLEIROS DO BRASIL - STAB, 7, 1999, Londrina. Anais... Londrina: Sociedade dos Técnicos Açucareiros e Alcooleiros do Brasil, 1999, p. 137-140.

DILLEWIJN, C. Van Botany of sugarcane. Walthan: Chronica Botanica, 1952. 371p.

JULIEN, M.H.R. Testing ripeners: problems and prospects. In: CONGRESS OF INTERNATIONAL SOCIETY OF SUGAR CANE TECHNOLOGISTS, 16, 1977, São Paulo. Proceedings... São Paulo: International Society of Sugar Cane Technologists, 1977. v. 2, 1791-1809. 
LANDELL, M.G.A.; SILVA, M.A. Manual do experimentador - Melhoramento da cana-de-açúcar. In: METODOLOGIA DE EXPERIMENTAÇÃO: ENSAIOS DE COMPETIÇÃO EM CANADE-AÇÚCAR. Pindorama: Instituto Agronômico - IAC, 1995. p.3-9. (Apostila de Treinamento Interno)

LANDELL, M.G.A.; SILVA, M.A. As estratégias de seleção da cana em desenvolvimento no Brasil. Visão Agrícola, Piracicaba, v.1, p.18-23, 2004.

LUCCHESI, A.A.; FLORENCIO, A.C.; GODOY, O.P.; STUPIELLO, J.P. Influência do ácido 2-cloroetil fosfônico na indução de perfilhamento em cana-de-açúcar (Saccharum spp.) - Variedade NA 56-79. Brasil Açucareiro, Rio de Janeiro, v. 93, n.4, p.19-27, 1979.

MELOTTO, E.; CASTRO, P.R.C.; GODOY, O.P.; CÂMARA, G.M.S.; STUPIELLO, J.P.; IEMMA, A.F. Desenvolvimento da cana-de-açúcar cultivar NA56-79 proveniente da propagação de colmos tratados com ethephon. In: ANAIS DA E.S.A. “LUIZ DE QUEIROZ”, 1987, Piracicaba. Anais... Piracicaba: Escola Superior de Agricultura "Luiz de Queiroz", 1987, v.44, p. 657-676.

MILHOLLON, R.W.; LEGENDRE, B.L. Influence of ethephon on plant population and yield of sugarcane (Saccharum spp. hybrids). Plant Growth Regulator Society of America, LaGrange, v. 23, n. 1, p. 17-30, 1995.

NAILWAL, T.K.; GUPTA, V.K.; SAND, N.K.; PANT, R.C. Role of ethylene in tillering of sugarcane (Saccharum officinarum L.). Physiology and Molecular Biology of Plants, Nova Delhi, v. 10, n. 1, p. 127-130, 2004.

PRADO, A.P.A. Perfilhamento e produção da cana-de-açúcar (Saccharum spp.) em função da densidade de plantio. 1988. 69p. Dissertação (Mestrado) - Escola Superior de Agricultura "Luiz de Queiroz" - Universidade de São Paulo, Piracicaba.

PRADO, H. Solos do Brasil: gênese, morfologia, classificação, levantamento e manejo. $3^{\mathrm{a}} \mathrm{ed}$. Piracicaba: H. do Prado, 275p. 2003.
RODRIGUES, J.D. Fisiologia da cana-de-açúcar. Botucatu: Instituto de Biociências - Universidade Estadual Paulista, 1995. 99p. (Apostila)

ROMERO, E.R.; SCANDALIARIS, J.; RUFINO, M.; DURAN, A.; SOTOMAYOR, L.; QUIROGA, V.; MORALES, M. Actualizacion de las recomendación de manejo de glifosato como madurador de la caña de azucar. Avance Agroindustrial, Tucuman, v.21, n.22, p.22-27, 2000.

SHETIYA, H.L.; DENDSAY, J.P.S. Morpho-physiological and quality traits in sugarcane in response to post emergence treatment with 2-chloroethyl-phosphonic acid. Indian Sugar, Nova Delhi, v.41, n.1, p.37-40, 1991.

SILVA, M.A.; LANDELL, M.G.A.; CAMPANA, M.P.; XAVIER, M.A. Produtividade de mudas sob diferentes densidades de plantio, em viveiro oriundo de cultura de meristema. In: CONGRESSO NACIONAL DA SOCIEDADE DOS TÉCNICOS AÇUCAREIROS E ALCOOLEIROS DO BRASIL - STAB, 8, 2002, Recife. Anais... Recife: Sociedade dos Técnicos Açucareiros e Alcooleiros do Brasil, 1999, p. 538-543.

TOMLIN, C. The pesticide manual: incorporating the agrochemicals handbook. Surrey: British Crop Prot. Publish, 1994. 1341p.

VERRI, A.R.; PITELLI, R.A.; CASAGRANDE, A.A.; CASTRO, P.R.C. Reguladores vegetais no enraizamento e desenvolvimento de gemas de cana-de-açúcar tratadas termicamente. Anais da E.S.A. "Luiz de Queiroz", Piracicaba., v.40, p. 381-394, 1983.

WIEDENFELD, B. Enhanced sugarcane establishment using plant growth regulators. Journal American Society of Sugarcane Technologists, Canal Point, v. 23, p.48-61, 2003. 